\title{
Os sentidos do morar sob a ótica dos usuários dos Centros de Atenção Psicossocial: experimentações do viver na cidade de Santos, São Paulo, Brasil
}

\author{
The meanings of living from the perspective of Psychosocial Care \\ Centers' users: life experimentations in Santos, São Paulo, Brazil
}

Marina Mara Stracini (https://orcid.org/0000-0001-6502-2727) ${ }^{1}$

Maria Inês Badaró Moreira (https://orcid.org/0000-0001-5798-2023) ${ }^{2}$

${ }^{1}$ Secretaria de

Desenvolvimento e Inclusão Social, Prefeitura Municipal

Estância Balneária Ilhabela.

R. Prefeito Mariano

Procópio de Araújo

Carvalho 86, Perequê.

11630-000 Ilhabela

SP Brasil.

mstracini@gmail.com

${ }^{2}$ Universidade Federal de

São Paulo. Santos SP Brasil.

\begin{abstract}
This research highlights housing as one of the dimensions of the lives of individuals who experience severe psychological suffering, which reverberates in their care and unique therapeutic plan. This paper aims to grasp the Psychosocial Care Centers (CAPS) users' meanings of their experiences of living in Santos (SP), Brazil. This qualitative research was conducted with users of different services through semi-structured interviews submitted to the thematic content analysis. This study identified how the conception of housing relates to protection, individuality, and affective memories that corroborate the construction of an expanded concrete life regarding living in freedom in the city, presenting plural housing located in different territories. Taking ownership of spaces reveals the possibilities and challenges inherent to social exchanges and daily experiences. Being and living in a house means having access to material and subjective goods, besides assuring care in freedom. However, there are still limitations in the effective exercise of social participation.
\end{abstract}

Key words Mental health, Housing, House, Personal autonomy
Resumo Esta pesquisa destaca a moradia como uma das dimensões da vida de indivíduos que vivenciam sofrimentos psíquicos graves, que reverbera em seu cuidado e plano terapêutico singular. O objetivo deste artigo é apreender os sentidos das experiências de morar para os usuários dos Centros de Atenção Psicossocial (CAPS) do município de Santos, estado de São Paulo. Pesquisa qualitativa realizada com usuários de diferentes serviços por meio de entrevistas semiestruturadas submetidas a análise de conteúdo temática. $O$ estudo identificou que a noção de casa remete a proteção, individualidade e memórias afetivas que corroboram a construção de uma vida concreta ampliada no viver em liberdade na cidade, apresentando moradias plurais, localizadas em territórios distintos. As formas de apropriação dos espaços demonstraram as possibilidades e os desafios próprios das trocas sociais e vivências cotidianas. Estar e habitar uma casa representa ter acesso a bens materiais e subjetivos, assim como a garantia do cuidado em liberdade. Entretanto, ainda existem limitações no exercício da efetiva participação social.

Palavras-chave Saúde mental, Moradia, Casa, Autonomia pessoal 


\section{Introdução}

O processo de Reforma Psiquiátrica Brasileira e a consequente criação de uma ampla rede de cuidados em saúde mental demandam conhecer e elucidar o modo como as pessoas com sofrimento psíquico intenso se organizam em torno da moradia ao deixarem a tutela imposta pelas instituições totais. A planificação da Política Nacional de Saúde Mental do país teve como bússola os princípios da desinstitucionalização italiana ao redirecionar o modelo hospitalocêntrico para um desenho amplo e complexo de rede de serviços comunitários. Com esse princípio, buscou construir condições efetivas para o viver em liberdade e, assim, consolidar um plano de cuidados que ultrapassasse o ato de desospitalizar pessoas que estavam em situação de moradia em hospitais psiquiátricos ${ }^{1}$.

A desinstitucionalização caracterizou um trabalho prático de transformação que se inicia no interior dos manicômios, na medida em que propõe a alteração da forma como as pessoas eram "tratadas" (ou não tratadas), passando a se fundamentar em um conjunto complexo de ações que perpassassem o corpo social. O objeto de cuidado passou a ocupar-se da existência, e o processo de desinstitucionalização foi pautado não na vida produtiva, mas na produção da vida, de sentido, de sociabilidade, da utilização de espaços coletivos e de convivência, que levou a um desmonte gradual dos manicômios ${ }^{2}$.

Entre as condições concretas para deixar romper com os espaços asilares e promover a garantia da vida na cidade, foram criados os Serviços Residenciais Terapêuticos (SRT) para os internos de longa data em hospitais psiquiátricos com vínculos familiares e comunitários fragilizados ou interrompidos ${ }^{3}$. Somado a isso, para os egressos de internações, também foi instituído o auxílio-reabilitação psicossocial, denominado Programa de Volta para Casa (PVC) ${ }^{4}$. Ambos compõem as estratégias de desinstitucionalização que integram a Rede de Atenção Psicossocial (RAPS).Embora a política de saúde mental tenha buscado efetivar a vida em liberdade no âmbito do processo de desinstitucionalização brasileira, existem ainda muitos desafios ${ }^{5}$, e a demanda por moradia parece ser um dos grandes desafios da vida citadina.

A moradia constitui elemento fundamental para sustentação do bem-estar físico e psíquico de pessoas com sofrimento psíquico intenso, possibilitando a retomada dos direitos de cidadania, integrando o viver em liberdade. À pri- meira vista, pode-se considerar uma casa como um elemento rigidamente geométrico e espacial. Por outro lado, trata-se de espaço de acolhimento, caracterizando, também, espaço de conforto, passível de condensar e defender a intimidade ${ }^{6}$. De certo, nesses espaços são forjadas as vivências das cenas cotidianas, das histórias de vida e dos efeitos das trocas e valores sociais, como: afetos, dinheiro, poderes, entre outros símbolos 7 .

A ideia de casa está relacionada a experiências complexas e concretas de reconhecer o uso do tempo e do espaço com ritmos domésticos e afetivos, a partir do uso de objetos e oportunidades da vida diária, centradas na particularidade de cada indivíduo, como acontece com os diferentes moradores de uma casa ${ }^{8}$. Também como espaço de apropriação, a moradia é um dos principais elementos no processo de inserção, integração e manutenção de pessoas com sofrimento psíquico intenso no meio social ${ }^{8}$.

Ao considerar a moradia como um espaço de legitimação das relações afetivas e interpessoais, das trocas e da contratualidade cotidiana, resgata-se, também, a dimensão subjetiva das formas de morar e de pertencer a um espaço que se chama "seu". A partir da perspectiva de proteção, de espaço integrador e de recolhimento, parece relevante que os próprios usuários dos CAPS elucidem a experiência de habitar uma casa a partir do processo de cuidado em liberdade e das ações de atenção psicossocial. Assim, o objetivo deste estudo foi apreender os sentidos das experiências de morar para as pessoas que vivenciam o sofrimento psíquico intenso e fazem acompanhamento nos Centros de Atenção Psicossocial do município de Santos-SP.

\section{Método}

Este estudo privilegiou a pesquisa qualitativa no intuito de explorar a realidade social e o dinamismo da vida individual e coletiva dos sujeitos, considerando a riqueza dos significados de sua existência ${ }^{9}$. A coleta de dados foi realizada por meio de entrevista semiestruturada seguindo um encontro dialógico a partir de itens norteadores. Respeitados o interesse em falar sobre o tema e a disponibilidade, todos assinaram o Termo de Consentimento Livre e Esclarecido voluntariamente com anonimato assegurado por nomes fictícios. O estudo foi aprovado pela Comissão de Ética em Pesquisa com Seres Humanos da Universidade Federal de São Paulo, com parecer 2.777.375. 
Os participantes foram dez pessoas com acompanhamento em CAPS de modalidade III, localizados em diferentes regiões do município. Optou-se por abordar dois usuários em cada um dos serviços, a fim de elucidar realidades em diferentes territórios. Cinco participantes têm histórico de internação de longa permanência, e cinco não passaram por hospitais psiquiátricos com manutenção de cuidados no CAPS mesmo em momentos de maior desestabilização psíquica. Foram entrevistadas cinco pessoas do sexo feminino e cinco do masculino, com idades entre 39 e 65 anos. Quatro homens se identificaram como negros, enquanto cinco mulheres e um homem se declararam brancos. Quanto à escolaridade, quatro entrevistados apresentaram ensino fundamental incompleto, um ensino fundamental completo, dois com ensino médio completo, um com ensino superior incompleto, um com ensino superior completo e apenas um não alfabetizado. Sobre a condição socioeconômica, dois não possuíam renda fixa e contavam com apoio de familiares, enquanto os demais eram aposentados ou recebiam algum benefício - Benefício de Prestação Continuada (BPC) ou Programa de Volta para Casa (PVC).

As entrevistas foram registradas em gravador digital, transcritas e submetidas à análise de conteúdo temática, operacionalizadas em três etapas: pré-análise, exploração do material e tratamento dos resultados obtidos com interpretação em diálogo com a revisão narrativa de estudos sobre o tema ${ }^{9}$. Para efetivação da análise, foram relacionados três temas recorrentes: concepção de moradia; formas de morar e relações com o espaço e o território. O primeiro tema buscou apreender o significado de moradia a partir de sua importância, memórias e perspectivas. O segundo elucida a moradia em suas possibilidades e limitações territoriais, sociais e econômicas. $\mathrm{O}$ terceiro tema identifica a forma como os usuários se apropriam de seus lares.

\section{Resultados e discussão}

A cidade de Santos tem importante papel histórico na Reforma Psiquiátrica Brasileira, uma das pioneiras a promover efetivas transformações nos modos de cuidar em Saúde Mental, a partir da intervenção na antiga Casa de Saúde Anchieta, em maio de 1989. As transformações promovidas pela desinstitucionalização desencadearam a configuração de serviços comunitários inspirados na psiquiatria democrática italiana, com implantação de uma rede de atenção psicossocial composta por serviços abertos e regionalizados ${ }^{10}$. Atualmente, a Rede de Atenção Psicossocial é composta por 34 unidades de atenção básica à saúde; cinco CAPS adulto de modalidade III; um CAPS Álcool-drogas de modalidade III; um CAPS Álcool-Drogas Infanto Juvenil de modalidade III; três CAPS Infantis; três Serviços Residenciais Terapêuticos; uma Seção de Reabilitação Psicossocial; três Unidades de Pronto Atendimento; uma equipe de Consultório na Rua; e o Serviço de Atendimento Móvel de Urgência (SAMU).

Os participantes residem próximo aos CAPS, em distintos territórios da cidade, seja em casas isoladas, quartos em moradias coletivas ou apartamentos populares. As moradias situam-se em área urbana de uma cidade litorânea com grande desigualdade social, característica que acirra os desafios habitacionais de uma cidade turística do litoral Sul paulista com elevado custo de vida. É possível circular pelo jardim na organizada orla da praia e se deparar com moradias precárias em morros a poucos quarteirões de distância. $\mathrm{Na}$ região central, as casas comerciais históricas se transformaram em grandes moradias coletivas, com sublocação de quartos, também conhecidos como cortiços. A cidade abriga enorme região periférica com palafitas construídas sobre o mangue.

\section{Concepção de moradia}

As concepções sobre moradia remetem a um espaço potente para trocas, construções de laços e relações humanas. Primordialmente, diferenciam casa como estrutura física, enquanto uma moradia é o local em que realizam o ato de morar e fazer pequenas tarefas domésticas. Assim, o habitar, diferente do estar, conduz a uma visão dinâmica no uso da casa ou da moradia, considerando o tempo e o espaço a partir de relações que se estabelecem tanto material como também subjetivamente no jogo íntimo entre estar e habitar ${ }^{11}$. Podem ser considerados como modos de apresentar a necessidade intrínseca ao ser humano de um abrigo $^{8}$ e um espaço para exercício de atividades significativas em suas particularidades culturais, sociais, ambientais e temporais com as quais constituem o cotidiano em um mundo particular.

A respeito do imaginário de proteção e abrigo trazido com a noção de moradia, Tugny analisa o lugar chamado de casa como o primeiro abrigo, assim como uma tentativa de proteção que se dá 
no imaginário de Adão ao ser expulso do paraíso com suas mãos cruzadas sobre o rosto num gesto de defesa para enfrentar a chuva ${ }^{8}$. Essa situação precária possibilitou uma reflexão acerca das fraquezas e necessidades humanas em sua nudez original frente aos elementos que a casa traz como abrigo e proteção. Nessa perspectiva, a moradia pode ser entendida como espaço funcional em resposta necessária às condições e agressões do mundo e sustenta um lugar simbólico de proteção subjetiva. Essa noção de proteção comparece em algumas falas:

Dentro de casa ninguém vai te pegar, ninguém vai te machucar. A gente tem mais segurança. (Ivan)

É nosso lar, lugar onde a gente se acolhe. Porque tem muita gente na rua, né? Que não tem o que comer... é muito importante ter um lugar. (Álvaro)

Ah, moradia é tudo né? Você se abriga das ruas, do frio, da violência. (Fausto)

Diante da experiência do sofrimento psíquico intenso e em suas histórias de vida, seus desejos e falas foram muitas vezes invalidados ${ }^{12}$. A sensação de habitar foi invalidada com a não legitimação de suas vivências em espaços protetores. Também é possível identificar que a moradia remete à sensação genuína e concreta de proteção, uma vez que, unanimemente, aparece como espaço de segurança, recolhimento, onde pode-se proteger do mundo externo e acolher individualidades.

Se a moradia abarca um espaço funcional e protetivo às condições impostas pelo mundo, é necessário que responda às necessidades das pessoas, de modo que a casa seja capaz de suportar e atravessar momentos de crise e instabilidades psíquicas. Assim, se a casa "ideal" se apresenta como um sistema de proteção, ela também comporta frestas, à medida que nela também se vivenciam medos, angústias e inseguranças. A relação íntima entre habitante e casa faz com que as impressões da casa mudem ao longo do tempo e dos acontecimentos que ela suscita ou acolhe ${ }^{8}$. As falas abaixo ilustram memórias de moradas anteriores.

[...] eu fui criado no interior, com meus avós... Lá nós não tínhamos condições, [...] eu era uma pessoa que apanhei muito, tomava soco no nariz, meu nariz sangrava. A minha mãe pensa que eu não gosto dela. Mas tudo o que aconteceu, eu fiquei muito chateado, porque minha avó falou pra mim que eu fui abandonado. Aí, eu comecei sair pra rua desde pequenininho. (Henrique)

Muitas lembranças... A mais forte é a casa em São Paulo na década de 60 com meus pais, em ple- no centro de SP, centrão de SP, no bairro do Bexiga... é meio magico, né? Porque é um tempo que não volta mais, [...] que eu tenho saudade. E Santos também, né? Quando eu morava com qualidade de vida, mais perto do mar. (Gabriela)

Pode-se dizer que a moradia é um espaço integrador de vivências, memórias e afetações que corroboram a nossa construção individual e social. O morar implica espaço físico e subjetivo. Os relatos dos entrevistados mostram que a casa remete a lembranças de comida, ambientes vividos, laços afetivos, relações familiares com mãe, pai, infância e, também, fragilidades da vida, condições sociais e financeiras de muitas restrições. Em muitos aspectos do espaço habitado e do leque de vivências que o acompanha, a moradia ocupa lugar de suporte para construir a própria vida, uma vez que também indica um possível exercício da cidadania, tal como valorizado por Fausto:

Morar num lugar é ter endereço próprio, você ser uma pessoa reconhecida pela sociedade. Por pior que seja o lugar, você é uma pessoa, você pode ter conta, tudo... se o cara não tem um endereço, ele não pode ter conta nem nada! Quer dizer, a gente tem (moradia). (Fausto)

A moradia como unidade física suscita o lugar onde as pessoas podem ser encontradas e onde passam boa parte do tempo, principalmente à noite, quando não estão trabalhando ou realizando outras ações cotidianas externas. Também, pode-se considerar que a divisão dos espaços internos da casa indica funções diferentes, tais como asseio, alimentação, convívio, educação, repouso, e também espaço de produção. Os móveis e objetos, além de declararem situação financeira, revelam traços peculiares dos habitantes ${ }^{13}$.

No caso de pessoas que vivenciam o sofrimento psíquico grave e que viveram internações em algum momento de sua vida, o fato de passarem a ter um endereço próprio é fundamental para o exercício da cidadania. E, assim, podem ampliar as aspirações de adquirir outros bens de valores sociais e podem, também, ampliar suas exigências de qualidade de bem viver, considerando possível sonhar com uma casa ideal. Em alguns exemplos, são elucidados estes desejos ampliados:

[...] casa de bloco... igual um apartamento com muito conforto, que tivesse tudo! Televisão, DVD, geladeira, micro-ondas, uma pessoa. (Álvaro)

Eu vejo uma casa com conforto, uma casa que tenha televisão, computador, micro-ondas, geladeira, DVD... eu penso nisso, né? Uma casa com conforto [...] no nosso espaço. Nosso lar... a cama para descansar, lugar para gente almoçar, essas coi- 
sas todas! Que é nosso lar, aonde a gente se acolhe, nosso refúgio. (Álvaro)

Uma casa bonita, uma casa funcional, uma casa que eu possa ter plantas, muitas plantas, que eu possa levar minhas netas, que elas curtam. (Gabriela)

Embora a concepção de moradia trazida pelos entrevistados seja essencialmente marcada pela noção de proteção e intimidade, essa noção também acompanha algumas projeções e idealizações de um espaço confortável e de acolhimento. $\mathrm{Na}$ realidade estudada, todos desejam morar em melhores instalações. Os aspectos do funcionamento social estão significativamente associados à autonomia e aos modos de morar ${ }^{14}$. Ainda que a moradia responda a uma necessidade basal, parece que os anseios desse grupo se expandem ao confrontar limitações sociais.

As experiências de moradia são dinâmicas, e a privacidade apresentada pelos seus espaços indica determinados níveis de liberdade com efeitos transformadores na vida dos sujeitos. Ter um espaço próprio para viver é como deixar de ser apenas cuidado para cuidar de si, de seus pertences e administrar a própria vida ${ }^{14}$. Os relatos apontam o desejo por um espaço próprio, um espaço íntimo onde se possa ter seus bens resguardados e que correspondam aos seus prazeres e necessidades. Assim como valorizam ter liberdade para se expressar livremente e relacionar com outras pessoas.

\section{Formas de Morar}

Notadamente, parecem persistir espectros do estigma que atravessam a vida dos ex-internos de hospitais psiquiátricos e se perpetuam mesmo que vivam em suas próprias casas na cidade. A política de saúde mental brasileira buscou responder a preocupações habitacionais com a criação dos SRT e do PVC ${ }^{1}$. Nos últimos anos, os propósitos da desinstitucionalização vêm sofrendo ataques, e retrocessos evidenciam vários desafios cotidianos para os usuários de CAPS. A realidade da vida das pessoas que demandam atenção e cuidados em saúde mental está sendo afetada por questões políticas e administrativas ${ }^{15}$. Consequentemente, é preciso ressaltar as limitações no campo do trabalho, geração de renda, possibilidades de trocas e condições de provimento de gastos gerais, além da alimentação e demais necessidades básicas amplificadas pela condição do sofrimento psíquico intenso.

Diante das características territoriais, é possível perceber as diferenças entre as condições ha- bitacionais de acordo com a região da cidade. $\mathrm{O}$ valor do aluguel de um quarto em moradia coletiva (cortiço) com banheiro externo pode chegar a 600 reais ou mais, como ilustrado abaixo:

É um quarto...e eu pago aluguel. R\$600,00. (...) Um quarto só, com banheiro do lado de fora. (...) eu queria mais espaço... As coisas são muito em cima uma da outra. É um quarto, não é uma casa. (Carlos)

Eu acho que é caro. Eu sou aposentada. E, hoje, o minimo de um aluguel é mais que a metade de um salário-mínimo. (Gabriela)

O CAPS localizado em uma das regiões mais pobres da cidade foi o primeiro serviço aberto na cidade, ainda em 1989, e acolhe moradores dos morros, da região das palafitas e bairros populosos mais periféricos. Para os entrevistados desse serviço, a moradia é vista como espaço de proteção, mas também os deixa expostos à violência, assim como a outros moradores dessa região. Álvaro revela que aguarda pelo deferimento do benefício assistencial (BPC) para se mudar. Em sua fala, coloca em evidência uma violência estrutural que elucida o cotidiano de pessoas que residem em condições semelhantes.

...lá é favela, tem muita boca de fumo, então tem muito traficante. Sai tiroteio, eu fico com medo. O pessoal lá anda tudo meio assustado, porque a polícia passa lá direto. Aí confunde a gente que é trabalhador com marginal (...) E lá é um beco. É um inferno! [...] Então, a polícia invadiu a minha casa lá, revistaram meu cunhado [...] teve uma vez que eu tava em casa assim...e aí o policial me pegou pelo gogó e foi me arrastando, quase me mata sufocado, e meu irmão vendo...sem fazer nada! Entrava polícia lá direto, para pegar bandido...agora não está entrando mais. (Álvaro)

Diferente dessa experiência, os participantes acolhidos pelo CAPS localizado em uma região nobre relatam outra realidade. Enquanto aqueles desejam uma casa de bloco e ter eletrodomésticos "básicos", estes gostariam de morar em um lugar com mais acesso ou possibilidades. Dois entrevistados vivem em bairros na região da orla e descrevem maior amplificação do convívio e das trocas sociais. Um relata que antes de adoecer residia com a família, e, após adoecer, perdeu seus bens. Hoje, aposentado por incapacidade para o trabalho, passou a morar em uma pensão. Uma entrevistada reside em apartamento próprio de conjunto habitacional com filho, netos e bisnetos. A violência não é referida, e suas necessidades são desejo de melhorias na condição de moradia.

Olha, poderia morar num lugar melhor, viu? Mais perto da praia. Eu moro no Macuco. É um 
lugar como um qualquer, é fundo. Fundo não é legal! Não tem o que ver. Se fosse mais perto da praia podia ficar mais perto da praia, sair para passear. Eu também fico cansado, sabe? Então fico dentro de casa vendo televisão. (Fausto)

Eu moro com meu filho... minha mãe faleceu, e, então, eu moro com meu filho. Meu filho mora comigo, o apartamento é meu. E tenho dois netos que moram junto também. Eu que criei os dois netos. É BNH, apartamento de três quarto e uma sala grande. Eu fico num quarto e meus netos e meus bisnetos ficam em outro quarto. Meu filho no outro. Gostaria de morar sozinha... porque eles dão muito trabalho, muita preocupação. (Eliana)

Dois CAPS se localizam em território próximo um ao outro e com realidades semelhantes. Em geral, os usuários desses CAPS residem em quartos alugados de pensão ou cortiço, com a família ou sozinhos. Uma usuária relatou que, anteriormente ao processo de adoecimento, trabalhava e residia em uma moradia melhor, mas, atualmente, com parcos recursos financeiros, passou a residir em um quarto de moradia coletiva.

Por exemplo, que as moradias coletivas... eu moro em uma! Gostaria que fossem locais de irmandade mesmo, de diálogo, de abertura de bem querer, mas acontece que não são, né? Eu acho que isso existe em todo lugar, mas as moradias coletivas, assim... algumas tem uma dinâmica bem perversa mesmo. Tem quartos com banheiro e tem quartos sem banheiro. O meu é sem banheiro no quarto. É coletivo. (Gabriela)

As configurações espaciais das moradias apresentam características consequentes da desigualdade social. Assim, a necessidade de habitação é confrontada pela insuficiência dos espaços, fazendo com que as moradias exijam uma organização que possibilite a adequação ao espaço concreto disponível ${ }^{16}$.

Lá em casa, nós não temos nada pra comer, aí eu ganho cesta básica, levo lá pra casa, aí falta as coisas, aî tem as contas pra pagar, entendeu? Então, tudo isso aí, nós ficamos chateados. É conta de luz, é conta de água e botijão de gás. E nós ficamos muito triste. [...] quando eu vou dormir, o meu quarto não tem nada. Eu queria ter uma televisão, um rádio [...]. Eu fico pensando "poxa, vida! Então, eu não quero mais morar em casa. É assim, ter o meu espacinho, entendeu? (Henrique)

Ivan também reside em um quarto coletivo típico dos cortiços da cidade, não possui eletrodomésticos nem espaço para cozinhar. Assim como todos os moradores, utiliza o banheiro coletivo externo. Juntamente com Henrique e Joana, faz suas refeições diárias no CAPS e frequenta o local para suas necessidades fisiológicas por ter um espaço com banheiro e instalações privadas e limpas. Nesses casos, as limitações da moradia levam as pessoas a recorrerem ao CAPS, inclusive, para necessidades essenciais, diante das suas precárias condições socioeconômicas.

Esses aspectos contribuem para desvelar como as condições materiais incidem nas demais dimensões da vida dos sujeitos e transmutam-se em condições subjetivas inibidoras para o viver na cidade. Assim, o CAPS responde às faltas intrínsecas à questão da moradia, somadas a fatores de ordem social, econômica e cultural. São necessidades em diferentes esferas da vida que mantêm forte relação entre as demandas por habitação em interface com o campo da saúde mental ${ }^{17}$. Em análise de cenas de circulação pelo bairro e ampliação do acesso a serviços comerciais, de saúde e cultura, observou-se que, a partir do morar, ocorrem apropriação e reapropriação do corpo, da casa e da rua de diferentes formas. Assim, pode-se considerar que o poder aquisitivo, a localização das moradias e os encontros com outras pessoas permitem estabelecer novos laços e construções sociais que passam a ser circunstâncias fundamentais para consolidação do viver na cidade ${ }^{18}$.

Quanto ao CAPS localizado na região central, por acolher muitos moradores dos cortiços existentes no território, a dimensão da moradia é dilema comum aos planos terapêuticos construídos junto aos usuários. As condições de moradias em cortiços são ilustradas no seguinte relato:

É um quarto...eu pago aluguel. (...) Ah, pago pelo banheiro...que não é coletivo, que é só pra mim e pra minha mulher. $R \$ 600,00$. (...) Eu gosto, mas não pretendo passar o resto da minha vida lá. (...) Queria mais espaço...As coisas são muito em cima uma da outra. É um quarto, não é uma casa. Uma casa que eu escolhesse (Carlos).

As formas de morar desses usuários nesse território assemelham-se em diversos aspectos. Em geral, a ausência de recursos financeiros imposta pelas limitações de possibilidades de trabalho e demais formas de geração de renda e vínculos familiares fragilizados fazem com que essas pessoas tenham condições habitacionais parecidas, tanto no que diz respeito aos espaços físicos (pensões, cortiços, moradias populares) quanto ao acesso aos parcos recursos materiais. Como elemento da vida humana, importa destacar que esses modos de morar são fatores importantes para reabilitação psicossocial e para o cuidado do sofrimento psíquico quando relacionado a maior ou menor inserção na sociedade ${ }^{19}$. 
Mesmo considerando as adversidades presentes, a casa se mostra um espaço de garantia de proteção, o que se observa quando relacionam a moradia com um lugar seguro:

Eu acho que, por pior que seja o espaço [mesmo coletivo], é melhor do que ficar na rua. Porque ficar na rua, o que significa? Encurtar a vida, porque não existe retaguarda lá e paz nenhuma. Lá eles cortam o cabelo, levam para tomar banho e jogam na rua de novo. Em alguns lugares, tem repressão aos moradores de rua, então eu acho que não existe situação pior que a dos moradores de rua. (Gabriela)

Quanto ao papel do CAPS, em algumas situações, este se apresenta como extensão da moradia, refletindo sua importância como resposta às ausências concretas que permeiam a moradia e um direito básico como a alimentação. É demarcado, também, como importante espaço de trocas, afetos e cuidado, semelhante ao que também esperam da moradia. Ao que parece, ainda que não seja exatamente o seu papel na política de saúde mental, pode-se observar que são respostas às necessidades de moradia dos usuários. $\mathrm{O}$ CAPS emerge, também, como um lugar de apoio e suporte para aqueles que necessitam morar de maneira independente e lidar com diversos desafios impostos pelo cotidiano da vida em sociedade, afirmando-se como importante locus de cuidado e proteção para esses indivíduos.

\section{Relações com o espaço e o território}

Embora possuam inúmeras limitações em suas moradias, pode-se afirmar que as casas oferecem prazer e aconchego. Ao chegarem à casa, sabem que possuem um espaço resguardado para si, independentemente de características objetivas, tal como assinalado nos relatos abaixo, ao valorizarem as atividades realizadas cotidianamente:

Cuido do cachorro, passo pano no meu quarto. (...) Gosto de cozinhar. Quem cozinha é meu filho. (Eliana)

Ah, quando eu tô em casa eu gosto de cozinhar, fazer um miojo, fazer um arroz. E quando a comida tá pronta eu só esquento no microondas. (Henrique)

Ler, ver TV, descanso. Tô sempre mexendo em alguma coisa... (Gabriela)

Eu gosto que tem um bar perto, tem um mercadinho... eu vou lá. Posso tomar refrigerante, de vez em quando tomo uma cerveja sem álcool. (Carlos)

O espaço físico denota a possibilidade de ocupar, organizar, decorar e vivenciar a casa de forma plural e, ao mesmo tempo, particular, respondendo aos anseios pessoais. A identidade social está intimamente ligada à liberdade de poder se expressar e ao poder decisional das ações ${ }^{20}$. No interior de suas casas, (re)organizam-se e exercem sua autonomia e individualidade, em alguns momentos de forma mais flexível, em outros, de forma mais limitada - a depender das relações presentes em seus contextos cotidianos ${ }^{19}$. Assim, quando Carlos afirma que gosta do fato de morar perto de um bar e um mercadinho, observa-se o exercício de trocas e valores sociais que demarcam uma construção de autonomia.

Andar pelo território permite construir um caminho em que se podem expressar gostos, preferências e vontades, circulando pelo bairro em que vivem e degustando o que desejam ${ }^{18}$. Esse é um exemplo de como as trocas cotidianas acontecem nos pequenos detalhes, principalmente para aqueles com histórico de institucionalização, como no caso de Carlos, que, durante as entrevistas, valoriza sua casa ao relembrar o passado marcado por internações e eletrochoques: Lá na minha cidade, eu fui internado no manicômio. [..] Quase todo dia era choque na cabeça. O bairro e o trânsito nas ruas do entorno da moradia tornam possível a chance de pertencimento como cidadão, de modo que é possível atravessar as paredes do domínio pessoal para a cidadania, vivendo situações de ineditismo dos encontros e novas descobertas favorecidas pelas relações de troca ${ }^{21}$. Ao contrariar o modelo societal excludente em que o indivíduo é simplificado por meio de um diagnóstico, inibido em suas relações, o histórico de internações emerge como divisor que atinge a posição social, a imagem pública, bem como outros aspectos da vida.

Viver na cidade aponta uma série de experiências comuns ao cotidiano citadino. Embora esses entrevistados vivam o sofrimento psíquico intenso, sejam cuidados no território e residam em condições para criar laços, recriar espaços e com isso recriar também suas relações, vivem algumas restrições. Ainda que as possibilidades de trocas existam, muitas vezes são limitadas, o que pode ser evidenciado ao assinalarem as poucas interações sociais nos territórios, como a circulação no comércio local e vínculos com algumas pessoas da vizinhança. Ao analisar as relações amplamente, é possível observar que são frequentes as relações com as pessoas e atividades ofertadas pelos CAPS. Essa característica ressalta as relações afetivas estabelecidas entre trabalhadores e usuários como espaço de experimentação para a vida e de expansão de laços de amizade 
e relações afetivas com pessoas com as quais se identificam ${ }^{22}$, afirmando o viver com práticas de solidariedade e amizade.

Quanto às relações familiares, à liberdade que possuem para utilizar espaços, bens e receber visitas, por exemplo, estão atreladas às formas de relação com os demais moradores da casa. Percebe-se que, diante de vínculos familiares fragilizados, a possibilidade de apropriação da casa também é diminuída.

Minha irmã diz que eu moro com ela... eu durmo na casa dela, é diferente! Eu só durmo! Depois de manhã eu tomo banho na casa dela, mas agora colocaram meu chuveiro. (Beatriz)

Mesmo após anos morando com a irmã, Beatriz considera não residir, mas apenas dormir e tomar banho no local, demonstrando o baixo grau de pertencimento com relação à sua moradia. Os espaços, os móveis e objetos não são dispostos ao acaso. Correspondem às particularidades dos modos de organização e expressão de seus moradores, apresentando diferentes formas de uso e ocupação. Assim, para apropriar-se de uma moradia, é preciso também se sentir parte $\operatorname{dela}^{20}$.

Como aspecto relevante, a cidade turística litorânea possibilita uma série de espaços públicos para frequentar, e, ainda assim, os entrevistados indicam que não transitam por esses lugares, limitando o percurso aos seus bairros, por meio dos comércios, da vizinhança entre outros espaços familiares. Os entrevistados indicaram que realizam passeios, vão ao cinema ou participam de atividades culturais quando ofertadas pelo CAPS. Existe uma interação social que se amplia como estímulo à participação em atividades culturais e sociais, como se observa maior circulação pelo território:

Ah, eu gosto de jogar bola... faço um curso de grafite. (Álvaro)

Pegar ônibus e ir pra um lugar é legal. Andar pela Ana Costa é legal. Eu sou muito assim. Muito pé no chão mesmo, não almejo grandes eventos. (Gabriela)

O transporte público torna possível o acesso dos entrevistados a diferentes lugares e possibilita sua circulação entre os espaços sociais como qualquer cidadão $0^{15}$. É possível afirmar que ao habitar a cidade se encontram espaços de inserção em suas regras sociais, o que possibilita criar seus próprios espaços e apreender as regras do morar ao vivenciar a moradia e o seu entorno. A cidade passa a proporcionar espaços para trocas e encontros por meio da movimentação nos territórios. Se a loucura, por muito tempo, ficou isolada da cidade por meio de instituições fechadas e de controle, após as reformas psiquiátricas ocorridas, a cidade pode ser tomada novamente pela loucura, consolidando o combate ao que foi produzido pelo domínio manicomial, desde que garantido o cuidado em liberdade.

\section{Considerações finais}

Embora se tenha observado uma série de contradições, a compreensão e visualização do todo permitem a percepção de que, majoritariamente, essas pessoas possuem recursos limitados, moradias precárias e relações familiares conturbadas. A escassez de recursos materiais e financeiros faz com que alguns usuários demandem o CAPS por condições limitadas de arcar com as despesas com moradia, alimentação e outras necessidades fundamentais.

Sobre a circulação pela cidade, percebe-se que ocorre de forma limitada, uma vez que os usuários costumam caminhar pelos bairros mais próximos a suas moradias e construir relações com as pessoas locais. Assim, ao fazerem compras no comércio local, andarem de ônibus ou irem para o CAPS, vão estabelecendo importantes relações de troca de mensagens, afetos e palavras. Contudo, referem poucos vínculos com a vizinhança. Não foram observadas ações específicas das equipes dos CAPS com relação ao trabalho direto voltado às moradias, porém algumas necessidades dos usuários são supridas a partir da estrutura física e as atividades externas que as unidades e suas equipes fornecem. Outra ambivalência observada é a apropriação das moradias e do território. Ainda que os entrevistados se refiram às atividades de cuidado cotidiano com a casa e no que gostam de fazer em seus lares, parecem não sentir liberdade de escolhas, como, por exemplo: de receber visitas ou até mesmo cozinhar, assim como também relatam reclamações familiares quanto ao incômodo que causam em pequenos atos corriqueiros. Essa informação não elucidada neste estudo evidencia a necessidade de aprofundar os estudos sobre as relações com familiares.

É possível concluir que, mesmo tendo acesso a um cuidado em liberdade, existem lacunas para efetivar uma vida com participação social. Para que a circulação pela cidade e a apropriação dos espaços seja fortalecida, é necessário pensar em políticas que incentivem o aumento da inserção dessas pessoas na vida da cidade. Uma importante contribuição para o fomento dessas práticas tem sido o empréstimo do poder contratual re- 
alizado pelos técnicos das equipes dos CAPS, em que, por meio de atividades externas, incentivam a apropriação dos espaços da cidade, fortalecendo relações de troca e convívio com as mais diversas pessoas.

\section{Colaboradores}

MM Stracini e MIB Moreira trabalharam igualmente na elaboração deste artigo que é fruto da dissertação de mestrado da primeira autora sob supervisão da segunda.

\section{Referências}

1. Brasil. Ministério da Saúde (MS). Secretaria de Atenção à Saúde. DAPES. Coordenação Geral de Saúde Mental, Álcool e Outras Drogas. Saúde mental no SUS: cuidado em liberdade, defesa de direitos e rede de atenção psicossocial. Relatório de gestão 2011-2015. Brasília: MS; 2016.

2. Rotelli F, Leonardis O, Mauri D. Desinstitucionalização, uma outra via. In: Nicácio F, organizador. Desinstitucionalização. São Paulo: Hucitec; 1990. p. 17-60.

3. Brasil. Ministério da Saúde (MS). Portaria GM n.106, de 11 de fevereiro de 2000. Institui os Serviços Residenciais Terapêuticos no âmbito do Sistema Único de Saúde para o atendimento ao portador de transtornos mentais. Diário Oficial da União 2000; $11 \mathrm{fev.}$

4. Brasil. Lei no 10.708 , de 31 de julho de 2003. Institui o auxílio-reabilitação psicossocial para pacientes acometidos de transtornos mentais egressos de internações. Diário Oficial da União 2003; 01 ago.

5. Moreira MIB, Guerrero AVP, Bessoni EA. Entre desafios e aberturas possíveis: vida em liberdade no contexto da desinstitucionalização brasileira. Saude Soc [periódico de internet]. 2019 [acessado 2019 maio 9]. [cerca de 5p] Disponível em: https://doi.org/10.1590/ S0104-12902019000003

6. Vasconcelos EM. Dispositivos residenciais em saúde mental - um campo aberto para os trabalhadores sociais: revisão de estratégias, tipologia e principais desafios políticos, teóricos e práticos. In: Rosa LCS \& Vasconcelos EM, organizadores. Saúde mental e serviço social: o desafio da subjetividade e da interdisciplinaridade. São Paulo: Cortez; 2000. p. 97-124. 
7. Pitta A. O que é a Reabilitação Psicossocial no Brasil, hoje? In: Pitta A, organizador. Reabilitação Psicossocial no Brasil. São Paulo: Hucitec; 2016. p. 27-36.

8. Tugny A, Kapp S, Baltazar A. Habitar uma casa. In: Furtado JP, Nakamura E, organizadores. Inserção Social e Habitação de Pessoas com Sofrimento Mental Grave. São Paulo: Editora FAP Unifesp; 2014. p. 351368.

9. Minayo MCS. O desafio do conhecimento: pesquisa qualitativa em saúde. $6^{\mathrm{a}}$ ed. Rio de Janeiro: Hucitec; 1999.

10. Kinoshita RT. Em busca da cidadania. In: Campos FCCB, Henrinque CMP, organizadores. Contra a maré à beira-mar: a experiência do SUS em Santos. São Paulo: Hucitec; 1997. p. 67-77.

11. Saraceno B. Libertando Identidades: da reabilitação psicossocial à cidadania possível. $2^{\mathrm{a}}$ ed. Rio de Janeiro: Te Corá Editora; 2001.

12. Kinoshita RT. Contratualidade e Reabilitação Psicossocial. In: Pitta A, organizador. Reabilitação Psicossocial no Brasil. 4a ed. São Paulo: Hucitec; 2016. p. 69-74.

13. Granerud A, Severinsson E. Preserving Integrity: experiences of people with mental health problems living in their own home in a new neighbourhood. Nursing Ethics [serial on the internet]. 2003 [cited 2020 jun 3]; 10(6):602-613. Available from: https:// doi.org/10.1191/0969733003ne650oa.

14. Fossey E, Harvey C, Mcdermott F. Housing and Support Narratives of People Experiencing Mental Health Issues: Making My Place, My Home. Front Psychiatry [serial on the internet]. 2020 [cited 2020 out 25]; 10(939):1-14. Available from: https://www.frontiersin.org/articles/10.3389/fpsyt.2019.00939/full.

15. Delgado PG. Reforma psiquiátrica: estratégias para resistir ao desmonte. Trab Educ Saude [periódico de internet]. 2019 [acessado 2019 maio 9]; 17(2): [cerca de 4 p.]. Disponível em: https://bit.ly/2I3TrKg

16. Tugny A, Kapp S, Baltazar A. Habitar, verbo intransitivo. In: Furtado JP \& Nakamura E, organizadores. Inserção Social e Habitação de Pessoas com Sofrimento Mental Grave. São Paulo: Editora FAP Unifesp; 2014. p. 85-102.

17. Rolin M. A Questão da Moradia em Saúde mental. In Mateus MD, organizador. Políticas de saúde mental: baseado no curso Políticas públicas de saúde mental, do CAPS Luiz R. Cerqueira. São Paulo: Instituto de Saúde; 2013. p. 169-175.
18. Massa PA, Moreira MIB. Na Casa e na Rua: Cenas dos Moradores de Serviços Residenciais Terapêuticos. Psicol Cienc Profissão 2021; 41(4):1-13.

19. Nakamura E, Carvalho EN. Reflexões Antropológicas sobre a Diversidade: Significados de Moradia e Construção de Pessoas. In: Furtado JP \& Nakamura E, organizadores. Inserção Social e Habitação de Pessoas com Sofrimento Mental Grave. São Paulo: Editora FAP Unifesp; 2014. p. 397-416.

20. Friesinger JG, Topor A, Bøe TD, Larsen IB. Materialities in supported housing for people with mental health problems: a blurry picture of the tenants. Sociology of Health \& Illness [serial on the internet]. 2020 [cited 2020 out 25]:1-17. Available from: https://onlinelibrary.wiley.com/doi/full/10.1111/1467-9566.13162

21. Moreira MIB, Andrade AN. Viver em liberdade: investidas no bairro e convívio com os vizinhos. In. Bragacampos F, Lancetti A, organizador. Saúde Loucura 9. Experiências da Reforma Psiquiátrica. São Paulo: Editora Hucitec; 2010. p. 353-370.

22. Moreira MIB, Onocko-Campos RT. Ações de saúde mental na rede de atenção psicossocial pela perspectiva dos usuários. Saude Soc 2017; 26(2):462-474.

Artigo apresentado em 30/10/2020

Aprovado em 13/10/2021

Versão final apresentada em 15/10/2021

Editores-chefes: Romeu Gomes, Antônio Augusto Moura da Silva 